\title{
Adherence of Human Basophils to Cultured Umbilical Vein Endothelial Cells
}

\author{
Bruce S. Bochner, Peter T. Peachell, Karen E. Brown, and Robert P. Schleimer \\ Department of Medicine, Division of Clinical Immunology, The Johns Hopkins University School of Medicine \\ at the Good Samaritan Hospital, Baltimore, Maryland 21239
}

\begin{abstract}
The mechanism by which circulating human basophils adhere to vascular endothelium and migrate to sites of allergic reactions is unknown. Agents have been identified which stimulate the adherence of purified basophils to cultured human umbilical vein vascular endothelial cells (HuVEC). Treatment of HuVEC with interleukin 1, tumor necrosis factor (TNF), bacterial endotoxin, and 12-O-tetradecanoylphorbol-13-acetate (TPA) resulted in time and dose-dependent increases of adhesiveness for basophils. Coincubation of basophils and HuVEC for 10 min with C5a, formyl-methionyl-leucyl-phenylalanine, the calcium ionophore $\mathbf{A 2 3 1 8 7}$, platelet-activating factor, TNF, and TPA also resulted in significant dose-dependent increases in basophil adherence; this effect resulted from activation of the basophil. Adherence of basophils to HuVEC was time and temperature dependent, required divalent cations, and was unaffected by glucocorticoids. Monoclonal antibody 60.3, directed against the $\beta$-subunit of the leukocyte adherence complex CD18, inhibited the binding of basophils to HuVEC. Adherence of basophils to vascular endothelium may be important in initiating basophil infiltrates in vivo.
\end{abstract}

\section{Introduction}

A variety of inflammatory responses in animals and man are accompanied by increased numbers of basophils. In guinea pigs, for example, the delayed local accumulation of large numbers of basophils after appropriate intracutaneous sensitization with heterologous proteins is termed cutaneous basophil hypersensitivity (1). In man, basophils have long been known to be important in atopic diseases, but their specific role in these reactions remains uncertain. Histamine release after allergen challenge of peripheral blood basophils has become firmly established as an in vitro model for immediate hypersensitivity, and correlates with the clinical manifestations of chronic allergic diseases such as symptom scores and skin test results $(2,3)$. Immediate type hypersensitivity reactions in the skin, nose, and lower airways, once thought to be an isolated monophasic response, are often followed in 3-12 h

Portions of this work were presented in abstract form (J. Allergy Clin. Immunol. 79:170; 1987).

Address reprint requests to Dr. Schleimer, Division of Clinical Immunology, The Johns Hopkins University School of Medicine at the Good Samaritan Hospital, 5601 Loch Raven Blvd., Baltimore, MD 21239.

Received for publication 25 August 1987 and in revised form 9 November 1987.

J. Clin. Invest.

(c) The American Society for Clinical Investigation, Inc.

$0021-9738 / 88 / 05 / 1355 / 10 \quad \$ 2.00$

Volume 81, May 1988, 1355-1364 by the gradual reappearance of a more sustained inflammatory reaction (4). Histological evaluation of these late phase allergic reactions in the skin and nose demonstrated a characteristic intense cellular infiltrate composed of neutrophils and eosinophils, as well as basophils $(5,6)$. Increases in the number of circulating basophils reportedly precede exacerbations of asthma, and increased numbers of basophils have also been found in vernal conjunctivitis, atopic and contact dermatitis, bronchial and nasal secretions, peripheral blood, skin test sites, and skin windows after allergen stimulation in allergic subjects (reviewed in reference 7). After intranasal antigen challenge, the release of histamine, which coincides with symptoms during the late phase, is not accompanied by a rise in prostaglandin $D_{2}$, suggesting that histamine released during the nasal late phase response is from basophils rather than mast cells (8).

The fact that basophils and basophil-derived mediators appear during inflammatory reactions suggests that mechanisms exist for the recruitment of basophils to the sites of these responses. This requires that circulating basophils first adhere to the vascular endothelium; subsequent diapedesis and chemotaxis then results in their appearance in the inflammatory infiltrate. This implies the existence of mechanisms for basophil chemotaxis, diapedesis, and/or adherence to vascular endothelium. While investigators have previously identified stimuli, including C5a, lymphokines, and serum from allergic donors, which are chemotactic for human basophils (9-12), there currently is no information regarding the mechanisms and regulation of basophil adherence to vascular endothelium.

Recently, techniques for the isolation and culture of human vascular endothelial cells $(\mathrm{HuVEC})^{1}$ from umbilical veins have enabled investigators to identify agents such as interleukin 1 (IL 1), tumor necrosis factor (TNF), lymphotoxin, bacterial endotoxin, and tumor promoting phorbol diesters that promote the adherence of neutrophils, eosinophils, and mononuclear cells by inducing the transient de novo expression of specific proteins on the surface of HuVEC (13-19). At least one such protein, termed E-LAM-1, has now been identified using monoclonal antibodies (20). Leukocyte adherence to endothelium and other substrates appears to be mediated through a family of adherence molecules normally present on the leukocyte cell surface; these molecules include the Mol, LFA-1, and p150,95 glycoproteins, collectively referred to as the CD18 antigens $(21,22)$. Recent reports have demonstrated the presence of Mol and LFA-1 antigens on the surface

1. Abbreviations used in this paper: DMSO, dimethylsulfoxide; HuVEC, human vascular endothelial cells; IFN, interferon- $\gamma$; LPS, $E$. coli lipopolysaccharide; PAF, platelet-activating factor (1-alkyl-2-acetyl-sn-glycero-3-phosphocholine); PAG, Pipes-buffered saline with $0.003 \%$ human serum albumin and $0.1 \%$ D-glucose; PAGC, PAG containing $1 \mathrm{mM} \mathrm{CaCl}$; PAGCM, PAG containing $1 \mathrm{mM} \mathrm{CaCl}_{2}$ and 1 $\mathrm{mM} \mathrm{MgCl}{ }_{2}$; PAGM, PAG containing $1 \mathrm{mM} \mathrm{MgCl}_{2}$; Pipes, piperazine- $N$ - $N^{1}$-bis(2-ethanesulfonic acid); TNF, tumor necrosis factor; TPA, 12-O-tetradecanoylphorbol-13-acetate. 
of human basophils, but p150,95 is apparently absent (23). Agents such as the bacterial peptide fMLP, the complement fragment C5a, calcium ionophore A23187, and phorbol diesters also stimulate leukocyte adherence, apparently by rapidly upregulating the number of preformed $\mathrm{CD} 18$ glycoproteins on the surface of the leukocyte (24-26). It remains uncertain whether CD18 antigens on leukocytes bind directly to endothelial cell E-LAM-1 antigens, but it is clear that separate mechanisms exist for the activation of leukocytes and endothelium to facilitate their adhesive interactions. We therefore have examined a variety of stimuli for their ability to promote basophil adherence to HuVEC. Several stimuli have been identified that act on HuVEC to induce adhesiveness for basophils. Additional stimuli have been found that promote basophil adherence by an effect primarily on the basophil. Since glucocorticoids are known to prevent the accumulation of leukocytes at inflammatory sites by inhibiting their adherence to the vascular endothelium, the effect of dexamethasone and hydrocortisone treatment of basophils on their ability to adhere to HuVEC has been studied. Finally, several aspects of basophil-HuVEC adherence have been characterized, including the kinetics of adherence, and dependence on temperature, divalent cations, and CD18 antigens.

\section{Methods}

Reagents. Dimethylsulfoxide (DMSO), dexamethasone, hydrocortisone, Pipes (piperazine- $N$ - $N^{1}$-bis[2-ethanesulfonic acid]), human serum albumin, fMLP, Escherichia coli serotype 0127:B8 bacterial lipopolysaccharide (LPS), 12-O-tetradecanoylphorbol-13-acetate (TPA), platelet-activating factor ([PAF], 1-alkyl-2-acetyl-sn-glycero-3phosphocholine) and lyso-PAF were purchased from Sigma Chemical Co., St. Louis, MO; M199 culture medium and RPMI 1640 medium with $25 \mathrm{mM}$ Hepes from Gibco Laboratories, Grand Island, NY; penicillin and streptomycin from M. A. Bioproducts, Walkersville, MD; calcium ionophore A23187 from Calbiochem-Behring Corp., La Jolla, $\mathrm{CA}$; and purified human IL 2 and interferon- $\gamma$ (IFN) from Genzyme Corp., Boston, MA. The following reagents were generously provided: purified human monocyte IL 1 by Dr. Charles A. Dinarello, Tufts University Medical School, Boston, MA; recombinant human tumor necrosis factor- $\alpha$ ([TNF], $5 \times 10^{7} \mathrm{U} / \mathrm{mg}$ ) by Dr. Michael Shepard, Genentech, South San Francisco, CA; recombinant human C5a (27) by Drs. Christopher J. Pazoles and Henry J. Showell, Pfizer Inc., Groton, CT; and monoclonal antibody 60.3 , a mouse IgG2a preparation recognizing the common $\beta$ subunit of the CD18 complex (28), by Drs. Patrick Beatty and John Harlan, University of Washington, Seattle, WA. Monoclonal antibody W6/32, a mouse IgG2a monoclonal against HLA A, B, C (29) was purchased from Accurate Chemical Co., Westbury, NY. Buffers used included PAG (Pipes buffer [25 mM Pipes, $110 \mathrm{mM} \mathrm{NaCl}, 5 \mathrm{mM} \mathrm{KCl}$ ] containing $0.003 \%$ human serum albumin, 0.1\% D-glucose), PAGM (PAG with $1 \mathrm{mM} \mathrm{MgCl}_{2}$ ), PAGC (PAG with $1 \mathrm{mM} \mathrm{CaCl}_{2}$ ), and PAGCM (PAG with $1 \mathrm{mM} \mathrm{CaCl}_{2}$ and 1 $\mathrm{mM} \mathrm{MgCl}$ ).

Isolation and culture of human umbilical vein endothelial cells. HuVEC were isolated from umbilical cord veins after collagenase digestion and grown in primary culture in M199 media supplemented with $20 \%$ fetal calf serum, antibiotics, heparin, and endothelial cell growth factor as previously described (14). No cell lines were passaged more than three times. Endothelial cells were allowed to grow to confluence on gelatinized 24-well culture plates $(\sim 250,000 \mathrm{HuVEC} /$ well) and confluence was verified by phase contrast microscopy before use in experiments. Endothelial cells were identified by their typical cobblestone morphology and the presence of Factor VIII antigen as detected by indirect immunofluorescence.

Purification of basophils. Human basophils were purified from venous blood of normal volunteers by centrifugation of EDTA-antico- agulated blood diluted with Pipes-diluted percoll (specific gravity 1.065 ) layered over cushions of Percoll (specific gravity $1.079 \mathrm{~g} / \mathrm{ml}$ ) as described elsewhere (30). Viability after purification was determined by the exclusion of erythrosin B and always exceeded $95 \%$. Counting of basophils was performed after staining with alcian blue. This purification procedure yielded basophils that ranged in purity from 1 to $17 \%$, with $>95 \%$ of contaminating cells being mononuclear leukocytes. For experiments using basophils of enhanced purity, basophils were further purified by passive sensitization with benzylpenicilloyl-specific IgE and elution over a benzylpenicillin-bound Sepharose 6MB affinity column as previously reported (31). Viability after this purification step was consistently $>90 \%$ and improved cell purity to at least $80 \%$. Unless otherwise indicated, cells were resuspended in PAGCM buffer before use in the HuVEC adherence assay.

Culture of basophils. In some experiments, basophils were cultured $\left(37^{\circ} \mathrm{C}\right.$, in a humidified atmosphere of $5 \% \mathrm{CO}_{2}, 95 \%$ air) for $20 \mathrm{~h}$ with 1 $\mu \mathrm{M}$ dexamethasone or hydrocortisone in RPMI 1640 medium with 25 mM Hepes supplemented with $10 \%$ autologous serum, $250 \mathrm{U} / \mathrm{ml}$ penicillin and $250 \mu \mathrm{g} / \mathrm{ml}$ streptomycin as indicated in the text. Glucocorticoids were diluted just prior to use from $0.1 \mathrm{M}$ stock solutions stored at $-20^{\circ} \mathrm{C}$ in DMSO; controls contained equivalent dilutions of DMSO or medium alone. Following culture, cells were washed once with PAG; viability and cell recovery always exceeded $85 \%$. As a positive control for glucocorticoid activity, aliquots of glucocorticoid-treated and control basophil suspensions were incubated for $45 \mathrm{~min}$ at $37^{\circ} \mathrm{C}$ with $0.1 \mu \mathrm{g} / \mathrm{ml}$ goat anti-human IgE, and histamine release measured as previously described (32).

Adherence of basophils to HuVEC. Previous studies using other leukocyte subpopulations have relied on radiolabelling (e.g., with ${ }^{51} \mathrm{Cr}$ ) of a readily obtainable, nearly pure population of cells to quantitate leukocyte adherence (14). This was not practical for these studies, since it is difficult to obtain sufficient quantities of basophils at adequate purity from most donors. Therefore, basophil adherence was monitored using cell-associated histamine as a basophil marker, allowing the use of basophil preparations of varying purity.

Two types of adherence assays were performed. First, the ability of various stimuli to induce adhesiveness in HuVEC for basophils was tested by preincubating $\mathrm{HuVEC}$ with various stimuli at $37^{\circ} \mathrm{C}$ in a humidified atmosphere of $5 \% \mathrm{CO}_{2}, 95 \%$ air for $15 \mathrm{~min}$ to $24 \mathrm{~h}$ (typically $4 \mathrm{~h}$, see text). Following stimulation, HuVEC were rinsed once with $1 \mathrm{ml}$ of warm $\left(37^{\circ} \mathrm{C}\right)$ PAGCM, and $0.5 \mathrm{ml}$ of warm PAGCM was then added to each well. $100 \mu$ l of cell suspension $\left(2-4 \times 10^{4}\right.$ basophils) was added to each well, and HuVEC and basophils were allowed to incubate for up to $1 \mathrm{~h}$ as indicated in the text (typically $10 \mathrm{~min}$, since longer incubation times may allow leukocyte diapedesis and migration underneath the monolayer to occur [33]). After incubation, the supernatants were harvested, centrifuged to remove cells, and saved for histamine analysis. The wells were then rinsed once with $1 \mathrm{ml}$ warm buffer to remove any remaining nonadherent cells. $1 \mathrm{ml}$ of $1.6 \%$ perchloric acid was then added to each well to lyse adherent basophils and precipitate proteins. Histamine content of supernatants and adherent cells was quantitated using an automated fluorometric assay (34). Percent histamine release and percent basophil adherence was then calculated by comparison to the histamine content of the starting basophil suspension after perchlorate lysis. All experiments were performed in duplicate, and replicates were excellent, with a coefficient of variation $<10 \%$.

To verify histamine recovery and demonstrate that histamine was neither metabolized nor adsorbed to plastic, gelatin, or endothelial cells, histamine in concentrations up to $25 \mathrm{ng} / \mathrm{ml}$ was added to rinsed monolayers of HuVEC after a 4-h incubation with IL 1 (4 U/ml), LPS $(100 \mathrm{ng} / \mathrm{ml})$, TNF $(1 \mathrm{ng} / \mathrm{ml})$, TPA $(30 \mathrm{ng} / \mathrm{ml})$, or medium alone. After a 10 -min incubation $\left(37^{\circ} \mathrm{C}, 5 \% \mathrm{CO}_{2}, 95 \%\right.$ air), supernatants were recovered and analyzed for histamine. Recovery of exogenously added histamine exceeded $95 \%(n=3)$. Similarly, greater than $90 \%$ of the histamine present in an aliquot of basophils added during the adherence assay could be accounted for after combining the amount of histamine released with the histamine content of adherent and nonad- 
herent cells. Adherence of purified basophils to HuVEC was verified using phase-contrast microscopy and was not due to leukocyte aggregation or adherence to plastic or gelatin under the assay conditions used. Alcian blue staining of adherent cells clearly revealed binding of individual basophils to cultured endothelial cells. Incubations of basophils with HuVEC for 20 min or longer, however, occasionally resulted in cell aggregation (see Results).

The second type of adherence assay was designed to examine the ability of agents to stimulate basophil adhesiveness. Because most of the stimuli that promote leukocyte-dependent adherence are secretagogues, significant histamine release would make measurements of the histamine content of adherent cells an invalid estimate of basophil adherence. However, since adherence of basophils to HuVEC can occur in the absence of calcium as long as magnesium is present (see Results), PAGM buffer was used in these experiments to prevent calcium-dependent histamine release that may have occurred with many of these stimuli. Unfortunately, attempts to separately pretreat small aliquots of basophils with these stimuli were unsuccessful due to problems with cell recovery and aggregation. Therefore, the ability of various stimuli to effect basophil adhesiveness to unstimulated HuVEC was assessed by coincubating HuVEC (washed once with $1 \mathrm{ml} \mathrm{PAGM)}$ with stimulus and $2-4 \times 10^{4}$ basophils (final volume $555 \mu \mathrm{l}$ ) at $37^{\circ} \mathrm{C}$ for $10 \mathrm{~min}$ in a humidified atmosphere of $5 \% \mathrm{CO}_{2}, 95 \%$ air. To examine whether HuVEC activation was occurring in this assay, other experiments were performed in which HuVEC alone were preincubated with these same stimuli for $10 \mathrm{~min}$. The stimuli were then either removed or allowed to remain to coincubate with basophils during a subsequent $10-\mathrm{min}$ adherence assay. Supernatants were then harvested, nonadherent cells removed by rinsing once with $1 \mathrm{ml}$ PAGM adherent cells were lysed, and histamine release and liberated cell-associated histamine quantitated as above. Under these conditions, histamine release did not occur. In all experiments, appropriate dilutions of stock solution vehicles for each stimulus were tested and found to have no effect on basophil histamine release or adherence to HuVEC in either assay.

Effect of 60.3 antibody on basophil adherence to HuVEC. In these experiments, HuVEC were pretreated for $4 \mathrm{~h}$, rinsed with $1 \mathrm{ml}$ PAGCM, and $200 \mu$ l PAGCM was added to each well. Immediately before the addition of $25 \mu \mathrm{l}$ cell suspension ( $4 \times 10^{4}$ basophils), $25 \mu \mathrm{l}$ of monoclonal antibody 60.3 or a control antibody preparation (W6/32) was added (final antibody concentration: $44 \mu \mathrm{g} / \mathrm{ml}$ ). Cells were allowed to incubate $\left(37^{\circ} \mathrm{C}, 95 \%\right.$ air, $\left.5 \% \mathrm{CO}_{2}\right)$ for $10 \mathrm{~min}$, nonadherent cells were rinsed, adherent cells lysed, and liberated cell-associated histamine measured as above. Experiments were performed in a smaller final incubation volume than other experiments in order to conserve reagents. In these assays, neither monoclonal antibody caused histamine release.

Effect of temperature and divalent cations on basophil adherence to $H u V E C$. To examine the effect of temperature on basophil adherence, $\mathrm{HuVEC}$ were first preincubated as above for $4 \mathrm{~h}$ at $37^{\circ} \mathrm{C}$ with optimal concentrations of several stimuli; HuVEC were then washed with PAGCM at $4^{\circ}, 22^{\circ}$, or $37^{\circ} \mathrm{C}$, and $0.5 \mathrm{ml}$ of buffer at the appropriate temperature was added. Adherence assays were performed by adding basophils $(100 \mu \mathrm{l})$ suspended in PAGCM buffer $\left(22^{\circ} \mathrm{C}\right)$; leukocytes were allowed to adhere to HuVEC for $10 \mathrm{~min}$ at the appropriate temperature (refrigerator, bench-top, or incubator), and basophil adherence quantitated as above.

To examine the effect of divalent cations on basophil adherence, HuVEC were preincubated as above and washed with warm buffer (PAG, PAGC, PAGM, or PAGCM); $0.5 \mathrm{ml}$ of appropriate buffer was then added. Basophils $(100 \mu \mathrm{l})$ suspended in appropriate buffer at $37^{\circ} \mathrm{C}$ were then added, allowed to adhere at $37^{\circ} \mathrm{C}\left(5 \% \mathrm{CO}_{2}, 95 \%\right.$ air $)$ for 10 min, and adherence quantitated as above.

\section{Results}

Endothelial cell stimulation enhances adhesiveness for basophils. Prior experiments have shown that stimuli such IL 1,
LPS, TNF, and TPA induce optimal adhesiveness in HuVEC for neutrophils within $4 \mathrm{~h}$ of incubation (14). We therefore tested the ability of these stimuli to promote adhesiveness in HuVEC for basophils by preincubating HuVEC for $4 \mathrm{~h}$; after washing the HuVEC, basophils were added, and allowed to adhere to HuVEC for $10 \mathrm{~min}$. Data in Fig. 1 demonstrate that in the absence of stimulus, basophil adherence was $20.8 \pm 3.0 \%$, while IL 1, LPS, TNF, and TPA produced dose-dependent increases in adherence of basophils to HuVEC. Optimal binding of basophils to HuVEC was induced by $4 \mathrm{U} / \mathrm{ml} \mathrm{IL} 1$ $(38.4 \pm 3.8 \%), 100 \mathrm{ng} / \mathrm{ml}$ LPS $(44.2 \pm 6.9 \%), 1 \mathrm{ng} / \mathrm{ml} \mathrm{TNF}$ $(45.1 \pm 5.4 \%)$, and $30 \mathrm{ng} / \mathrm{ml}$ TPA $(62.7 \pm 3.5 \%)$. At no time did adherence of basophils to HuVEC result in histamine release above that of background spontaneous release (top, Table I and data not shown). Stimuli such as PAF (0.1-1 $\mu \mathrm{M})$, IFN (1-10 ng/ml), and IL $2(1-100 \mathrm{U} / \mathrm{ml})$ did not induce adhesiveness in HuVEC for basophils (combined average for highest concentrations tested: $116 \pm 4 \%$ of control, $n=3$ ).

The kinetics of the acquisition of adhesiveness in HuVEC for basophils is shown in Fig. 2. Adhesiveness in HuVEC induced by IL 1, LPS, and TNF were similar, being half-maximal by $2 \mathrm{~h}$, and optimal after 4-6 h of incubation. Adherence induced by exposure of HuVEC to TPA was more rapid, with half-maximal and maximal increases after 15-30 min and $2 \mathrm{~h}$, respectively. Adhesiveness induced by all four stimuli gradually declined over $24 \mathrm{~h}$, but did not return to unstimulated values. To assess the role of protein and RNA synthesis in the acquisition of adhesiveness for basophils, two experiments were performed in which HuVEC were pretreated for $15 \mathrm{~min}$ with a protein synthesis inhibitor (cycloheximide, $1 \mu \mathrm{g} / \mathrm{ml}$ ) or an RNA synthesis inhibitor (actinomycin $\mathrm{D}, 1 \mu \mathrm{g} / \mathrm{ml}$ ) and then coincubated for $4 \mathrm{~h}$ without stimulus or with IL 1 (2 $\mathrm{U} / \mathrm{ml})$, TNF $(1 \mathrm{ng} / \mathrm{ml})$ or TPA $(10 \mathrm{ng} / \mathrm{ml})$. Neither drug affected unstimulated adhesiveness $(103 \pm 4$ and $119 \pm 4 \%$ of controls, respectively). Cycloheximide inhibited the increase induced by IL 1 and TNF ( $23 \pm 6$ and $38 \pm 1 \%$ inhibition, respectively) while having little activity in preventing TPA-induced adhesiveness ( $7 \pm 7 \%$ inhibition). Actinomycin D was more effective in blocking adhesiveness induced by TNF than by TPA ( $94 \pm 6$ vs. $26 \pm 26 \%$ inhibition). In the presence of IL 1 , actinomycin D was toxic for HuVEC, an effect that has been previously observed (35). In the studies displayed in Figs. 1 and 2, a 10-min incubation of basophils with HuVEC was used. However, as seen in Fig. 3, the adherence of basophils to HuVEC was time dependent, with increased adherence that was detectable after $5 \mathrm{~min}$, and maximal by $40 \mathrm{~min}$. Cell aggregation was occasionally observed microscopically when incubation periods exceeded $20 \mathrm{~min}$. Since longer incubation times may also allow leukocyte diapedesis and chemotaxis to occur, values at these longer time points may not simply reflect basophil-HuVEC adherence. Therefore, a 10-min incubation was used in all subsequent studies. As shown in Figs. 4 and 5, adherence of basophils to HuVEC was temperature dependent $\left(37^{\circ}>22^{\circ} \gg 4^{\circ} \mathrm{C}\right)$, and required either calcium or magnesium. Optimal adherence occurred at $37^{\circ} \mathrm{C}$ in the presence of both divalent cations. However, magnesium appeared to be more important for unstimulated and TPA-induced basophil adherence, while calcium and magnesium were equally effective cations for adherence stimulated by IL 1, TNF, and LPS.

To test whether contaminating nonbasophilic cells influenced the adherence of basophils to HuVEC, preparations of enhanced basophil purity (80-89\%) were used in 10-min 
A

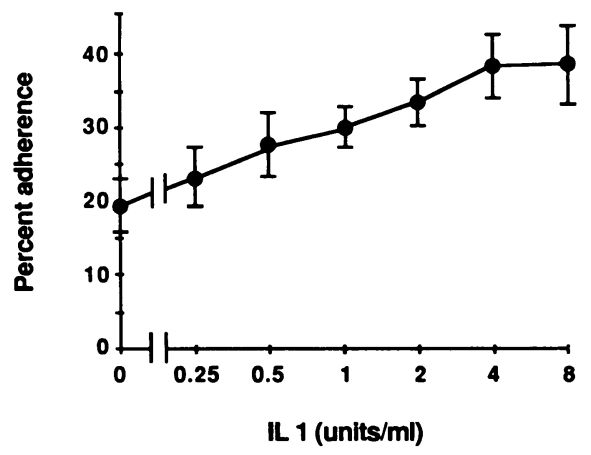

B

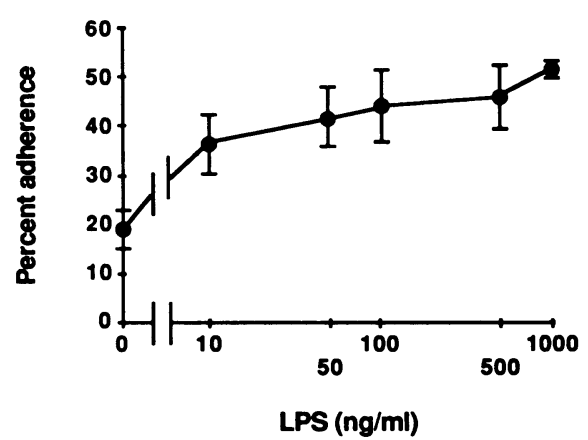

C
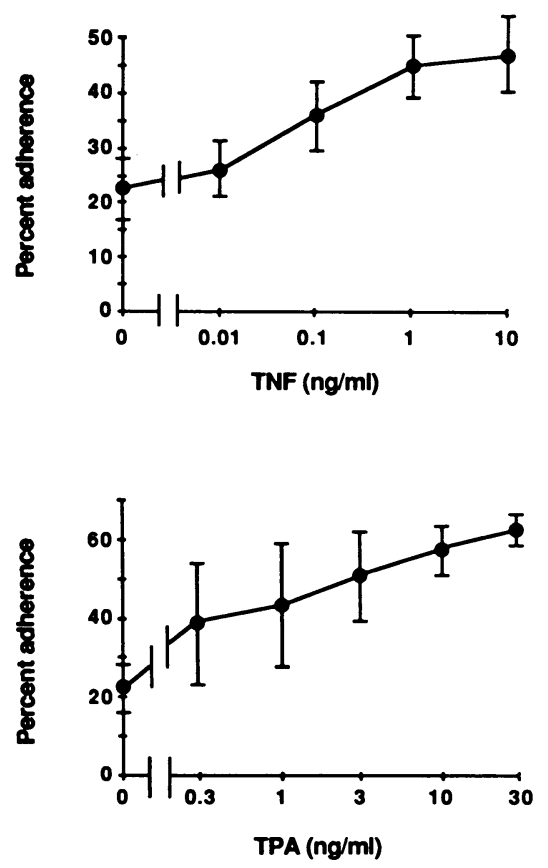

Figure 1. Stimulation of adhesiveness in HuVEC for basophils. HuVEC were incubated with the indicated concentrations of IL 1 $(A)$, LPS $(B)$, TNF $(C)$, and TPA $(D)$ for $4 \mathrm{~h}$, washed, and basophils (2-6\% purity) were allowed to adhere to HuVEC for $10 \mathrm{~min}$. Values represent the mean \pm SEM of duplicate determinations in three experiments.

adherence assays following $4 \mathrm{~h}$ stimulation of HuVEC with optimal concentrations of IL 1, TNF, TPA, and LPS. The results are shown in Table $I$ and are compared to data from
Fig. 1. Each of the stimuli tested induced adhesiveness in HuVEC for highly pure basophils. Spontaneous histamine release was slightly greater in two of three experiments using basophils of enhanced purity. Although both spontaneous and stimulated adherence were slightly lower using purified basophils, the ability of the stimuli to increase adherence was comparable to that seen with basophil preparations of lower purity. These effects were not due to the removal of contaminating mononuclear cells, because adherence assays using passively sensitized basophils in earlier fractions eluted from the affinity column (purity $\sim 5 \%$ ) showed identical adherence activity as the highly pure cells (data not shown). Since the relatively impure preparations often contain as many contaminating red blood cells as leukocytes and previous reports have suggested that red blood cells enhance the adherence of neutrophils to HuVEC, highly pure basophils were mixed with up to a 10fold excess of red blood cells; no effect on adherence was seen (data not shown). An additional possible explanation for these observed differences is that the adhesiveness of basophils decays during in vitro purification or culture; this is supported by experiments in which basophils maintained at $37^{\circ} \mathrm{C}$ or $4^{\circ} \mathrm{C}$ were serially tested for adherence to stimulated and unstimulated HuVEC. Compared with precultured freshly purified cells, basophils kept at $4^{\circ} \mathrm{C}$ had no decay of adhesiveness over $24 \mathrm{~h}$, while the adhesiveness of basophils cultured at $37^{\circ} \mathrm{C}$ declined during this time $(6 \pm 10 \%$ decay of adhesiveness vs. $58 \pm 11 \%$, respectively, $n=2$ ).

Effect of glucocorticoids on basophil adherence to HuVEC. One of the most important antiinflammatory effects of glucocorticoids is their ability to prevent leukocyte accumulation at the site of an inflammatory reaction by inhibiting leukocyte adherence to the endothelium. Therefore, experiments were performed to examine whether glucocorticoid pretreatment of basophils might alter their adhesiveness. Basophils cultured for $20 \mathrm{~h}$ with $1 \mu \mathrm{M}$ dexamethasone or hydrocortisone adhered to stimulated or unstimulated HuVEC as well as controls (Fig. 6). Glucocorticoids did have an identifiable effect on the basophils, since inhibition of anti-IgE-mediated histamine release was observed (Fig. 6, legend).

Stimulation of basophils enhances their adherence to HuVEC. Previous experiments with other granulocytes have demonstrated that several stimuli promote leukocyte adherence by an effect on the leukocyte. Similar experiments were therefore performed with basophils. Table II illustrates that coincubation of basophils and HuVEC for $10 \mathrm{~min}$ (column C) with several secretagogues, as well as PAF and TNF, induced rapid dose-dependent increases in basophil adhesiveness. This occurred without concomitant histamine release, since these experiments were done in the absence of calcium (36). Under these conditions, lyso-PAF and anti-IgE did not increase basophil adherence. With the stimuli used, exposure of basophils to stimulus was necessary to increase adherence, since preincubation of HuVEC alone for $10 \mathrm{~min}$, removal of the stimulus, and subsequent addition of basophils did not result in increased basophil adherence (Table II). Preincubation of HuVEC with stimuli for 10 min resulted in less basophil adherence than simultaneous addition of stimulus and basophils.

Basophil adherence to HuVEC is CD18-dependent. Adherence of other leukocyte subpopulations has been shown to be due to a CD18-dependent mechanism $(16,22,37)$. Experiments were therefore performed in which 60.3 , a monoclonal antibody directed against the common $\beta$ subunit of the CD18 


\begin{tabular}{|c|c|c|c|c|c|c|}
\hline \multirow[b]{3}{*}{ Basophil purity } & \multirow[b]{3}{*}{ Spontaneous ${ }^{t}$} & \multicolumn{5}{|c|}{ HuVEC pretreatment ${ }^{*}$} \\
\hline & & \multicolumn{5}{|c|}{ Percent histamine release } \\
\hline & & PAGCM & IL 1 & LPS & TNF & TPA \\
\hline \multicolumn{7}{|l|}{$\%$} \\
\hline 2 & $6^{8}$ & 5 & 4 & 5 & 5 & 4 \\
\hline 5 & 5 & 6 & 6 & 7 & 7 & 8 \\
\hline 6 & 9 & 9 & 9 & 8 & 8 & 7 \\
\hline 80 & 14 & 15 & 9 & 14 & 14 & 14 \\
\hline 85 & 6 & 6 & 6 & 9 & 8 & 9 \\
\hline \multirow[t]{2}{*}{89} & 10 & 10 & 10 & 8 & 9 & 10 \\
\hline & & \multicolumn{5}{|c|}{ Percent basophil adherence } \\
\hline Basophil purity & & PAGCM & IL 1 & LPS & TNF & TPA \\
\hline \multicolumn{7}{|l|}{$\%$} \\
\hline $2^{\prime \prime}$ & & $20^{8}$ & $41(205)^{7}$ & $46(230)$ & $52(260)$ & $65(325)$ \\
\hline 5 & & 24 & $44(183)$ & $55(229)$ & $49(204)$ & 67 (279) \\
\hline 6 & & 13 & $31(238)$ & $32(246)$ & $35(269)$ & $56(431)$ \\
\hline 80 & & 11 & $21(191)$ & $29(264)$ & $27(245)$ & $41(373)$ \\
\hline 85 & & 6 & $24(400)$ & $22(367)$ & $20(333)$ & $36(600)$ \\
\hline 89 & & 2 & $8(400)$ & $13(650)$ & $8(400)$ & $24(1200)$ \\
\hline
\end{tabular}

* HuVEC were pretreated for $4 \mathrm{~h}$ with IL 1 (4 U/ml), LPS (100 ng/ml), TNF (1 ng/ml), TPA (30 ng/ml), or PAGCM diluent alone. The stimuli were then removed, and HuVEC were tested during a 10-min incubation with basophils of different purity. ${ }^{\ddagger}$ Spontaneous histamine release was measured from separate aliquots of cell suspension incubated under similar conditions for 10 min without HuVEC. \$Values represent means of duplicate determinations. "Data for experiments with lower basophil purity are from Fig. 1. 'Percent of PAGCM control.

complex, was present during the basophil adherence assay. Spontaneous histamine release in the presence or absence of 60.3 was negligible $(5.5 \pm 0.6 \%$ and $4.2 \pm 0.6 \%$, respectively). As seen in Fig. 7, coincubation with 60.3 resulted in $42-78 \%$ inhibition of adherence to HuVEC of both low and high purity basophils. Since these experiments were performed in smaller final incubation volumes, which tends to facilitate cell settling, basophil adherence was greater than for all previous experiments.

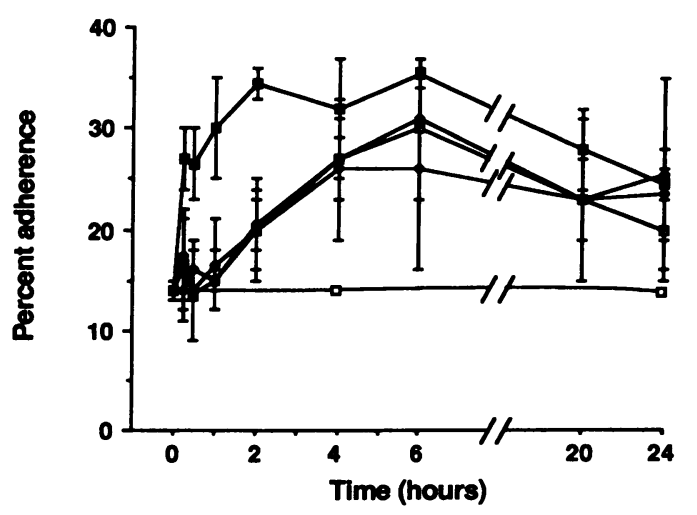

Figure 2. Kinetics of induction of adhesiveness in HuVEC for basophils. HuVEC were incubated with TPA $(n, 30 \mathrm{ng} / \mathrm{ml})$, IL $1(\square, 4$ $\mathrm{U} / \mathrm{ml})$, TNF $(\diamond, 1 \mathrm{ng} / \mathrm{ml})$, LPS $(\diamond, 100 \mathrm{ng} / \mathrm{ml})$, or PAGCM (ㅁ) diluent for the amount of time indicated, and then tested for adherence of basophils ( 2 and $4 \%$ purity) as in Fig. 1. Values represent the mean $\pm S E M$ of duplicate determinations in two experiments.

\section{Discussion}

The fact that basophils and basophil-derived mediators appear during a variety of inflammatory reactions suggest that mechanisms exist for the recruitment of basophils to the sites of these inflammatory responses. Several hypotheses for this have been

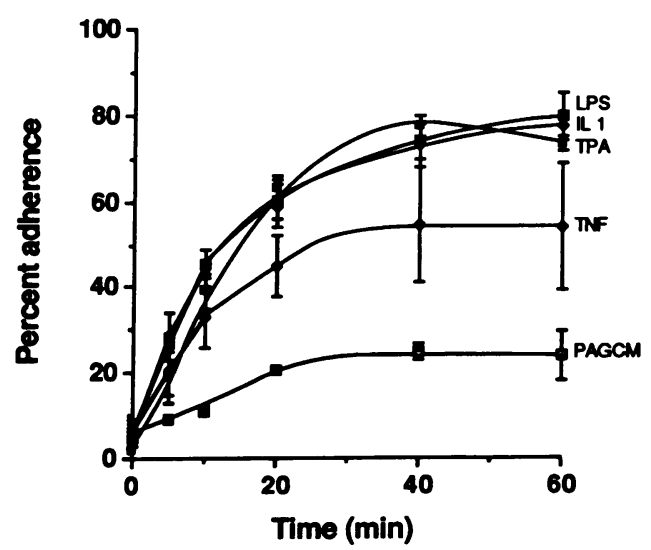

Figure 3. Kinetics of adherence of basophils to HuVEC. HuVEC were pretreated as in Fig. 2. The stimuli were removed, and basophils (3-8\% purity) were allowed to adhere to HuVEC for the amount of time indicated. Histamine release above spontaneous did not occur throughout the 60 -min incubation. Incubations for $20 \mathrm{~min}$ or longer occasionally resulted in microscopically visible cell aggregation. Values represent the mean \pm SEM of duplicate determinations in three experiments. 


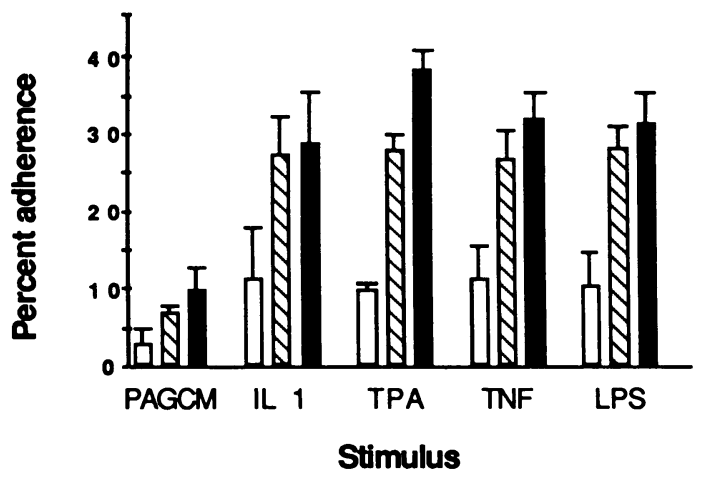

Figure 4. Temperature dependence of basophil adherence to HuVEC. HuVEC were pretreated as in Fig. 2. Basophils (1 and 2\% purity) were allowed to adhere to HuVEC for $10 \mathrm{~min}$ at the indicated temperatures. Values represent the mean \pm SEM of duplicate determinations in two experiments. $\square, 4^{\circ} \mathrm{C} ; \nabla, 22^{\circ} \mathrm{C} ; \mathbf{\square}, 37^{\circ} \mathrm{C}$.

proposed, including recruitment of basophils by chemotactic agents, and recruitment of circulating basophil progenitors $(9-12,38)$. A critical initial step in the emigration of cells from the circulation, however, involves the localized adherence of these circulating cells to the vascular endothelium adjacent to the inflammatory site. Our studies provide two possible mechanisms by which basophils could be recruited during inflammation. Stimuli such as PMLP, C5a, TNF, and PAF can directly activate the basophil to bind to endothelium, presumably by increasing expression of CD18 antigens if the basophil response to these agents is analogous to that of the neutrophil. Alternatively, we have demonstrated that stimuli such as IL 1, LPS, and TNF can activate HuVEC to acquire adhesiveness for basophils. Those stimuli that induce adhesiveness in HuVEC for basophils also induce adhesiveness in HuVEC for other granulocyte subpopulations including neutrophils and eosinophils (13-16). The kinetics of basophil adherence and the induction of adhesiveness in HuVEC for basophils resembles that for other granulocytes and appears to require RNA and protein synthesis, suggesting that basophils may be binding to the same inducible surface receptor previously described

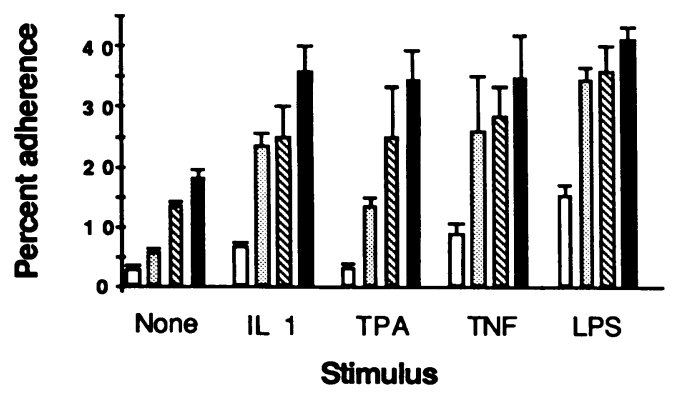

Figure 5. Basophil adherence to HuVEC requires divalent cations. HuVEC were pretreated as in Fig. 2. Basophils ( 2 and $6 \%$ purity) were allowed to adhere to HuVEC for $10 \mathrm{~min}$ in the indicated buffers in the presence or absence of $1 \mathrm{mM}$ calcium and magnesium. Values represent the mean \pm SEM of duplicate determinations in two experiments. $\square$, PAG; $\square$, PAGC; $\square$, PAGM; $\bullet$, PAGCM.

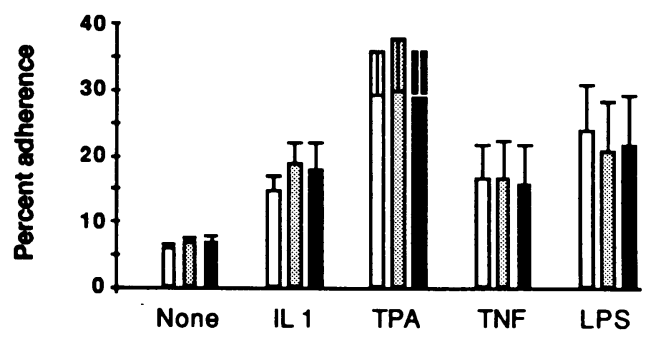

Figure 6. Effect of glucocorticoids on basophil adherence to HuVEC. Basophils (2-13\% purity) were cultured for $20 \mathrm{~h}$ with $1 \mu \mathrm{M}$ hydrocortisone ( $\square$ ), dexamethasone ( $\square$ ), or medium alone ( $\square$, control), washed, and then allowed to adhere for $10 \mathrm{~min}$ to HuVEC pretreated as in Fig. 2. Values represent the mean \pm SEM of duplicate determinations in five experiments. Control cultured basophils from two donors released histamine to anti-IgE (see Methods); release was inhibited by culture with hydrocortisone and dexamethasone $(43 \pm 5$ and $69 \pm 6 \%$ inhibition, respectively). For the remaining three experiments, basophils from two donors did not release to anti-IgE, and in one experiment, histamine release was not determined.

for neutrophil adherence (13-16, 20). Interestingly, endothelial cells at sites of various human dermatologic conditions display surface antigens (such as E-LAM-1) which can be stained by monoclonal antibodies $\mathrm{H} 4 / 18$ and $\mathrm{H} 18 / 7$ directed against this induced surface protein; this antigen is not expressed on normal human endothelium $(39,40)$. Furthermore, recent studies have shown that $\mathrm{H} 18 / 7$ is capable of inhibiting the adherence of neutrophils to activated HuVEC (40). While this suggests that endothelial cell activation occurs in vivo in association with certain pathologic skin conditions, it is not known whether endothelial cell activation occurs during late phase allergic reactions in man.

As with other leukocytes, basophil adherence to HuVEC is dependent on temperature and divalent cations $(41,42)$. The reason for the observed difference in cation requirements between calcium and magnesium seen only with unstimulated and TPA-induced adherence is unclear. Both unstimulated and maximally stimulated basophil adherence to HuVEC was greater than that previously reported for other granulocytes (14). The concentrations of the stimuli used that induce maximal adherence are similar for basophils, neutrophils, and eosinophils, except that approximately one-tenth the concentration of LPS is required for optimal adherence of basophils (14, 16). It is unclear whether the relative differences between the adherence of basophils and other granulocytes to HuVEC represents a true difference, or whether this simply reflects subtle differences in the adherence assays (e.g., leukocyte density) or methods used for leukocyte purification (e.g., isolation of basophils in the absence of serum), experimental conditions that result in activation of other basophil functions such as releasability (43). We also noted some donor-dependent variability in unstimulated adherence, suggesting the possibility of as yet undefined factors influencing endogenous basophil adhesiveness.

In these studies, culture with glucocorticoids was shown to have no effect on the ability of basophils to adhere to HuVEC. This is in agreement with studies on neutrophils, which further demonstrated that glucocorticoid treatment failed to inhibit the acquisition of adhesiveness in HuVEC stimulated by similar agents (44). Therefore, since glucocorticoids are known to inhibit cell accumulation during inflammatory reactions (such 
Table II. Basophil Adherence to HuVEC after Stimulation of Leukocytes and HuVEC

\begin{tabular}{|c|c|c|c|c|}
\hline \multirow[b]{2}{*}{ Stimulus } & \multirow[b]{2}{*}{ Concentration } & \multicolumn{3}{|c|}{ Experimental condition ${ }^{*}$} \\
\hline & & $\begin{array}{l}\text { Preincubation } \\
\text { only }\end{array}$ & $\begin{array}{l}\text { Preincubation and } \\
\text { coincubation }\end{array}$ & $\begin{array}{c}\text { Coincubation } \\
\text { only }\end{array}$ \\
\hline \multirow[t]{3}{*}{ f MLP } & $1,000 \mathrm{nM}$ & $101 \pm 8$ & $174 \pm 15^{\S}$ & $237 \pm 41^{8}$ \\
\hline & 100 & -1 & - & $156 \pm 17^{\S}$ \\
\hline & 10 & - & - & $107 \pm 29$ \\
\hline \multirow[t]{3}{*}{ A23187 } & $1,000 \mathrm{ng} / \mathrm{ml}$ & $115 \pm 10$ & $163 \pm 6^{\prime \prime}$ & $203 \pm 19^{11}$ \\
\hline & 200 & - & - & $169 \pm 20^{8}$ \\
\hline & 40 & - & - & $135 \pm 35$ \\
\hline \multirow[t]{3}{*}{ TPA } & $30 \mathrm{ng} / \mathrm{ml}$ & $106 \pm 2$ & $413 \pm 98^{\ddagger}$ & $442 \pm 92^{\S}$ \\
\hline & 3 & - & - & $289 \pm 76^{\ddagger}$ \\
\hline & 0.3 & - & - & $136 \pm 49$ \\
\hline \multirow[t]{3}{*}{ C5a } & $100 \mathrm{nM}^{* *}$ & $97 \pm 11$ & $168 \pm 8^{\prime \prime}$ & $161 \pm 17^{8}$ \\
\hline & $10^{* *}$ & - & - & $98 \pm 9$ \\
\hline & 1 & - & - & $86 \pm 6$ \\
\hline \multirow[t]{3}{*}{ TNF } & $1,000 \mathrm{ng} / \mathrm{ml}$ & $97 \pm 6$ & $114 \pm 12$ & $189 \pm 40^{\ddagger}$ \\
\hline & 100 & - & - & $179 \pm 37$ \\
\hline & 10 & - & - & $151 \pm 31$ \\
\hline \multirow[t]{3}{*}{ PAF } & $1,000 \mathrm{nM}$ & $123 \pm 13$ & $143 \pm 8^{\prime \prime}$ & $224 \pm 54^{\ddagger}$ \\
\hline & 100 & - & - & $209 \pm 48^{\ddagger}$ \\
\hline & 10 & - & - & $172 \pm 31$ \\
\hline \multirow[t]{2}{*}{ lyso-PAF } & $1,000 \mathrm{nM}$ & - & - & $97 \pm 14$ \\
\hline & 100 & - & - & $90 \pm 12$ \\
\hline anti-IgE & $0.5 \mu \mathrm{g} / \mathrm{ml}$ & - & - & $90 \pm 8$ \\
\hline
\end{tabular}

* Values are averages \pm SEM of duplicate determinations in three to six experiments of percent of control basophil adherence in the absence of calcium (see Methods) following (a) preincubation of HuVEC with stimulus for $10 \mathrm{~min}$ and removal of the stimulus before a 10-min incubation with basophils (1-11\% purity), (b) preincubation as in (a) without subsequent removal of the stimuli, or $(c) 10$ min coincubation of basophils with HuVEC and stimulus. Under these experimental conditions, none of the above stimuli caused histamine release. Unstimulated basophil adherence was $9 \pm 2 \%$.

${ }^{\ddagger}$ Using the paired Student's $t$ test, $P<0.05$.

${ }^{8} P<0.025$.

" $P<0.01$.

- not determined.

** Incubation of basophils with these concentrations of $\mathrm{C} 5 \mathrm{a}$, at $37^{\circ} \mathrm{C}$ in PAGCM buffer for $45 \mathrm{~min}$, resulted in $55 \pm 10 \%$ and $19 \pm 5 \%$ histamine release, respectively $(n=2)$.

as late phase allergic reactions) but do not inhibit the ability of basophils (and neutrophils) to adhere to HuVEC, the ability of antiinflammatory steroids to inhibit infiltrate formation may in part be due to their potent inhibition of the production of adherence-promoting factors such as IL 1 . Interestingly, macrophages have recently been shown to bear low affinity receptors for IgE, and apparently are stimulated to produce IL 1 following antigen challenge (45). Therefore, antigen-induced IgE-dependent IL 1 production by macrophages or other cells may be responsible, at least in part, for the recruitment of leukocytes during late phase allergic reactions.

Studies using other leukocyte subpopulations have shown that a variety of agents, including several chemoattractants
A

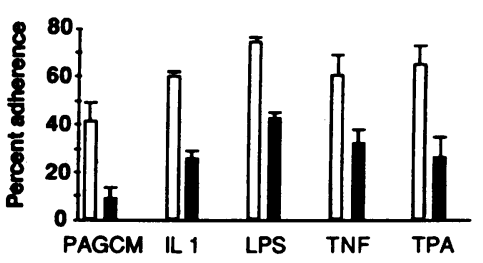

B

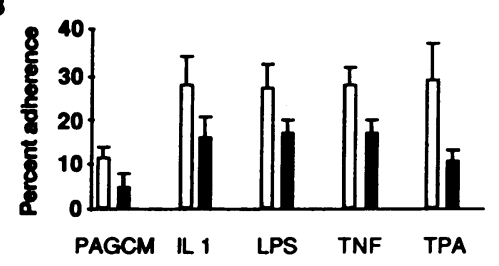

Simulus
Figure 7. Effect of monoclonal antibody 60.3 (घ) on basophil adherence. HuVEC were pretreated as in Figure 2. 10-min adherence assays were performed with lower purity basophils ( 1 and 5\%, $A$ ) and higher purity basophils $(83$ and $86 \%, B)$ in the presence of $44 \mu \mathrm{g} / \mathrm{ml}$ of 60.3. Values represent the mean \pm SEM of duplicate determinations in two experiments. Note different scales for A and B. Basophil adherence in the presence of $44 \mu \mathrm{g} / \mathrm{ml}$ of the control monoclonal anti-

body W6/32 did not differ from buffer (PAGCM, $\square$ ) controls, whether or not endothelial cells had been stimulated. For all data combined (both presence and absence of stimuli), adherence in the presence of W6/32 was $111 \pm 5$ and $112 \pm 5 \%$ of PAGCM controls for impure and highly pure preparations, respectively.

and secretagogues (fMLP, C5a, TPA, and the calcium ionophore A23187) increase adherence as a result of increasing the expression of CD18 glycoproteins on the surface of these cells (24-26). More recently, other stimuli lacking secretagogue activity have also been shown to promote leukocyte-dependent increases in adhesiveness, such as TNF and PAF (15, $16,46)$. To examine this aspect of basophil adherence, experiments were performed in the absence of calcium, since inclusion of this cation would have resulted in basophil degranulation and histamine release (36), making it impossible to accurately measure basophil adherence by the methods used in our studies. Due to technical constraints, the protocol used for these studies required the coincubation of leukocytes with HuVEC in the presence of stimuli; it is therefore possible that these stimuli could also have an acute effect on HuVEC. As shown in Table II, pretreatment of HuVEC with stimuli for 10 min and removal of the stimulus before the addition of basophils led to minimal changes in adherence, suggesting that stable activation of adhesiveness in HuVEC does not occur with these stimuli. While the most direct interpretation of these results is that the basophils are being activated to increase adherence, it is also possible that nonbasophilic leukocytes in the preparation are stimulated to release other factors which then influence basophil-HuVEC adhesiveness. Furthermore, the observation that preincubation of HuVEC with stimuli is less effective than coincubation alone suggests the possibility of degradation or uptake of stimuli by HuVEC or plastic, or the production by HuVEC of an inhibitor of adherence, an idea that is not without precedence (47).

It is of note that calcium was not necessary for basophildependent stimulation of adherence, and increased basophil adhesiveness can occur without degranulation. The mechanism by which the calcium ionophore A23187 stimulates basophil adhesiveness in these experiments is unclear, but could be due to an effect on intracellular calcium stores. Prior studies 
with neutrophils have demonstrated a rapid increase (i.e., within minutes) in the number of CD18 surface antigens after treatment with similar stimuli which is not prevented by inhibitors of messenger RNA or protein synthesis $(25,48)$. This has led to the hypothesis that there is a preformed intracellular pool of CD18 receptors (perhaps located in the secondary or "tertiary" granules in the neutrophil) which can be rapidly translocated to the cell surface $(25,48-50)$. Additional experiments are currently in progress to determine whether basophil expression of CD18 antigens and adhesiveness increases during degranulation; it will also be interesting to examine whether IgE-dependent stimulation of basophils (in the presence of calcium) can alter their adhesiveness.

Of particular interest was our findings that PAF, but not lyso-PAF, was capable of stimulating basophil adherence to HuVEC. To our knowledge, this is the first reported evidence that basophils respond to PAF, and suggests that this mediator may potentially be important in modulating other basophil functions. Extensive studies on the effects of PAF on basophil histamine release have consistently revealed no effect (data not shown). In addition, HuVEC are known to produce PAF in response to a variety of stimuli including IL 1 (51). While this may have contributed to the adhesive changes seen with basophils, whether the stimuli and experimental conditions used in our studies caused significant production of endothelial cell PAF was not determined.

We have also demonstrated that coincubation of basophils with an antibody directed against the common $\beta$ subunit of the CD18 complex leads to a marked inhibition of adherence of basophils to HuVEC. This is consistent with recent reports suggesting the presence of CD18-like molecules on the surface of basophils (23), and supports a functional role of these molecules in the adhesive interaction between basophils and HuVEC. The finding that blockage of the $\beta$ subunit with specific antibody does not completely inhibit basophil adherence to stimulated HuVEC is consistent with studies on neutrophils $(22,37)$. Thus, it is possible that additional cell surface structures not recognized by 60.3 are important for basophil adhesive interactions. The observation that 60.3 most strongly inhibited unstimulated adherence is intriguing; the significance of this finding is unclear, but perhaps suggests that the $\beta$ subunit may play a role in normal margination of basophils in vivo. It should also be noted that the smaller incubation volumes used in these blocking experiments, by facilitating cell settling and increasing cell density, may explain the higher values for basophil adherence seen in Fig. 7 .

While the mechanisms for late phase allergic responses remain unclear, stimulation of adhesiveness in vascular endothelium may be an important initiating factor in the development of the characteristic influx of granulocytes. Since granulocytes appear to share similar molecular mechanisms for adherence, it seems likely that it is the combined actions of both adherence-promoting factors and specific chemotactic factors which are required for the development of a specific cellular infiltrate. The delayed nature of late phase allergic reactions in vivo might therefore be due to the time necessary for both the production of endothelial cell activating factors and their subsequent action on vascular endothelium. Interactions with chemotactic factors, many of which are secretagogues, may also directly promote basophil adhesiveness and recruitment. The recent demonstration of a rare syndrome characterized by recurrent bacterial infections, impaired wound healing, gingivitis, and diminished pus formation has led to the discovery of a genetic deficiency in CD18 expression (24-26, 28). A recent review in the literature of a limited number of these patients have not reported any clinical signs of chronic allergic diseases such as rhinitis and asthma (26). If infiltrate formation and CD18 expression is important for late phase reactions and the clinical manifestations of chronic allergic diseases, this group of patients would be expected to have a decreased incidence of clinically apparent allergic disease, but should have the normal complement of subjects who manifest positive immediate type intradermal skin tests and have elevated serum levels of antigen-specific IgE. Such findings would strongly support the importance of CD18 antigens in chronic allergic diseases.

Recruitment of circulating leukocytes to tissue sites is an integral part of the inflammatory response. Mechanisms for leukocyte activation and chemotaxis have previously received much attention, but the importance of the vascular endothelium in modulating inflammatory infiltrate formation has only recently been appreciated. While basophils can directly respond to a variety of proinflammatory stimuli, the studies presented here delineate mechanisms by which agents, acting instead on endothelial cells, can lead to an egress of basophils from the circulation. Additional information regarding the relative roles of vascular endothelium and basophils in inflammatory conditions such as chronic allergic disease awaits further studies.

\section{Acknowledgments}

We wish to thank Drs. Charles A. Dinarello, Michael Shepard, Christopher J. Pazoles, Henry J. Showell, Patrick Beatty, and John Harlan for providing many of the essential reagents used in these studies. We also thank Dr. Lawrence M. Lichtenstein and his laboratory for performing the histamine measurements, Dr. Jane A. Warner for analysis of C5a-induced basophil histamine release, and Ms. Bonnie Evans for invaluable assistance in the preparation of this manuscript.

This work was supported by National Institutes of Health grants AM-31891 and AI-20136.

\section{References}

1. Askenase, P. W. 1977. Role of basophils, mast cells, and vasoamines in hypersensitivity reactions with a delayed time course. Prog. Allergy. 23:199-320.

2. Lichtenstein, L. M., P. S. Norman, and W. L. Winkenwerder. 1968. Clinical and in vitro studies on the role of immunotherapy in ragweed hay fever. Am. J. Med. 44:514-524.

3. Norman, P. S., L. M. Lichtenstein, and K. Ishizaka. 1973. Diagnostic tests in ragweed hay fever. J. Allergy Clin. Immunol. 52:210224.

4. Gleich, G. L. 1982. The late phase of the immunoglobulin Emediated reaction: a link between anaphylaxis and common allergic disease? J. Allergy Clin. Immunol. 70:160-169.

5. Solley, G. O., G. J. Gleich, R. E. Jordan, and A. L. Schroeter. 1976. The late phase of the immediate wheal and flare skin reaction. $J$. Clin. Invest. 58:408-420.

6. deShazo, R. D., A. I. Levinson, H. F. Dvorak, and R. W. Davis. 1979. The late phase skin reaction: evidence for activation of the coagulation system in an IgE dependent reaction in man. J. Immunol. 122:692-698. 
7. Mitchell, E. B., and P. W. Askenase. 1983. Basophils in human disease. Clin. Rev. Allergy 1:427-448.

8. Naclerio, R. M., D. Proud, A. G. Togias, N. F. Adkinson, Jr., D. A. Meyers, A. Kagey-Sobotka, M. Plaut, P. S. Norman, and L. M. Lichtenstein. 1985. Inflammatory mediators in late antigen-induced rhinitis. N. Engl. J. Med. 313:65-70.

9. Kay, A. B., and K. F. Austen. 1972. Chemotaxis of human basophils. Clin. Exp. Immunol. 11:557-563.

10. Hirsch, S. R., and J. H. Kalbfleisch. 1980. Existence of basophil chemotaxis in subjects with hay fever. J. Allergy Clin. Immunol. 65:274-277.

11. Ward, P. A., H. F. Dvorak, S. Cohen, T. Yoshida, R. Data, and S. S. Selvaggio. 1975. Chemotaxis of basophils by lymphocyte-dependent and lymphocyte-independent mechanisms. J. Immunol. 114:1523-1531.

12. Lett-Brown, M. A., D. A. Boetcher, and E. J. Leonard. 1976. Chemotactic responses of normal human basophils to C5a and to lymphocyte-derived chemotactic factor. J. Immunol. 117:246-252.

13. Bevilaqua, M. P., J. S. Pober, M. E. Wheeler, R. S. Cotran, and M. A. Gimbrone Jr. 1985. Interleukin 1 acts on cultured human vascular endothelium to increase the adhesion of polymorphonuclear leukocytes, monocytes, and related leukocyte cell lines. J. Clin. Invest. 76:2003-2011.

14. Schleimer, R. P., and B. K. Rutledge. 1986. Cultured human vascular endothelial cells acquire adhesiveness for neutrophils after stimulation with interleukin 1, endotoxin, and tumor-promoting phorbol esters. J. Immunol. 136:649-654.

15. Gamble, J. R., J. M. Harlan, S. J. Klebanoff, and M. A. Vadas. 1985. Stimulation of the adherence of neutrophils to umbilical vein endothelium by human recombinant tumor necrosis factor. Proc. Natl. Acad. Sci. USA. 82:8667-8671.

16. Lamas, A. M., C. M. Mulroney, and R. P. Schleimer. 1987. Studies on the adhesive interaction between human eosinophils and cultured vascular endothelial cells. J. Immunol. In press.

17. Pober, J. S., L. A. Lapierre, A. H. Stolpen, T. A. Brock, T. A. Springer, W. Fiers, M. P. Bevilaqua, D. L. Mendrick, and M. A. Gimbrone, Jr. 1987. Activation of cultured human endothelial cells by recombinant lymphotoxin: comparison with tumor necrosis factor and interleukin 1 species. J. Immunol. 138:3319-3324.

18. Cavender, D. E., D. O. Haskard, B. Joseph, and M. Ziff. 1986. Interleukin 1 increases the binding of human $B$ and $T$ lymphocytes to endothelial cell monolayers. J. Immunol. 136:203-207.

19. Yu, C.-L., D. Haskard, D. Cavender, and M. Ziff. 1986. Effects of bacterial lipopolysaccharide on the binding of lymphocytes to endothelial cell monolayers. J. Immunol. 136:569-573.

20. Pober, J. S., M. P. Bevilaqua, D. L. Mendrick, L. A. Lapierre, W. Fiers, and M. A. Gimbrone, Jr. 1986. Two distinct monokines, interleukin 1 and tumor necrosis factor, each independently induce biosynthesis and transient expression of the same antigen on the surface of cultured human vascular endothelial cells. J. Immunol. 136:1680-1687.

21. Bernstein, I. D., and S. Self. 1986. Joint report of the myeloid section of the second international workshop on human leukocyte differentiation antigens. In Leukocyte Typing II. Report of the second international workshop on human leukocyte differentiation antigens. E. L. Reinherz, B. F. Haynes, L. M. Nadler, and I. D. Bernstein, editors. Springer-Verlag, New York. 1-54.

22. Pohlman, T. H., K. A. Stanness, P. G. Beatty, H. D. Ochs, and J. M. Harlan. 1986. An endothelial cell surface factor(s) induced in vitro by lipopolysaccharide, interleukin 1 , and tumor necrosis factor- $\alpha$ increases neutrophil adherence by a CDw18-dependent mechanism. $J$. Immunol. 136:4548-4553.

23. deBoer, M., and D. Roos. 1986. Metabolic comparison between basophils and other leukocytes from human blood. J. Immunol. 136:3447-3454.

24. Springer, T. A., W. S. Thompson, L. J. Miller, F. C. Schmalstieg, and D. C. Anderson. 1984. Inherited deficiency of the Mac-1,
LFA-1, p150,95 glycoprotein family and its molecular basis. J. Exp. Med. 160:1901-1918.

25. Arnaout, M. A., H. Spits, C. Terhorst, J. Pitt, and R. F. Todd III. 1984. Deficiency of a leukocyte surface glycoprotein (LFA-1) in two patients with Mol deficiency. Effects of cell activation on Mol/ LFA-1 surface expression in normal and deficient leukocytes. J. Clin. Invest. 74:1291-1300.

26. Anderson, D. C., F. C. Schmalstieg, M. J. Finegold, B. J. Hughes, R. Rothlein, L. J. Miller, S. Kohl, M. F. Tosi, R. L. Jacobs, T. C. Waldrop, A. S. Goldman, W. T. Shearer, and T. A. Springer. 1985. The severe and moderate phenotypes of heritable Mac-1, LFA-1, p150,95 deficiency: their quantitative definition and relation to leukocyte dysfunction and clinical features. J. Infect. Dis. 152:668-689.

27. Franke, A. E., G. C. Andrews, N. P. Stimler-Gerard, C. Gerard, and H. J. Showell. 1988. Human C5a anaphylatoxin: gene synthesis, expression, and recovery of biologically active material from E. coli. Methods Enzymol. In press.

28. Beatty, P. G., J. M. Harlan, H. Rosen, J. A. Hansen, H. D. Ochs, T. H. Price, R. F. Taylor, and S. J. Klebanoff. 1984. Absence of monoclonal-antibody-defined protein complex in a boy with abnormal leukocyte function. Lancet. 1:535-537.

29. Barnstable, C. J., W. F. Bodner, G. Brown, G. Galfre, C. Milstein, A. F. Williams, and A. Ziegler. 1978. Production of monoclonal antibodies to group A erythrocytes, HLA, and other human cell surface antigens-new tools for genetic analysis. Cell. 14:9-20.

30. Warner, J. A., A. Reshef, and D. W. MacGlashan Jr. 1987. A rapid percoll technique for the purification of basophils. J. Immunol. Methods. 105:107-110.

31. MacGlashan, D. W., Jr., and L. M. Lichtenstein. 1980. Purification of human basophils. J. Immunol. 124:2519-2521.

32. Schleimer, R. P., L. M. Lichtenstein, and E. Gillespie. 1981. Inhibition of basophil histamine release by anti-inflammatory steroids. Nature (Lond.). 292:454-455.

33. Beesley, J. E., J. D. Pearson, A. Hutchings, J. S. Carleton, and J. L. Gordon. 1979. Granulocyte migration through endothelium in culture. J. Cell. Sci. 38:237-248.

34. Siraganian, R. P. 1975. Refinements in the automated fluorometric histamine analysis system. J. Immunol. Methods. 7:283-290.

35. Cavender, D., D. Haskard, N. Foster, and M. Ziff. 1987. Superinduction of $\mathrm{T}$ lymphocyte-endothelial cell (EC) binding by treatment of EC with interleukin 1 and protein synthesis inhibitors. $J$. Immunol. 138:2149-2154.

36. Kazimierczak, W., and B. Diamant. 1978. Mechanisms of histamine release in anaphylactic and anaphylactoid reactions. Prog. $\mathrm{Al}$ lergy. 24:295-365.

37. Anderson, D. C., L. J. Miller, F. C. Schmalstieg, R. Rothlein, and T. A. Springer. 1986. Contributions of the Mac-1 glycoprotein family to adherence-dependent granulocyte functions: structure-function assessments employing subunit-specific monoclonal antibodies. $J$. Immunol. 137:15-27.

38. Denburg, J. A., S. Telizyn, A. Belda, J. Dolovich, and J. Bienenstock. 1985. Increased numbers of circulating basophil progenitors in atopic patients. J. Allergy Clin. Immunol. 76:466-472.

39. Cotran, R. S., M. A. Gimbrone Jr., M. P. Bevilaqua, D. L. Mendrick, and J. S. Pober. 1986. Induction and detection of a human endothelial activation antigen in vivo. J. Exp. Med. 164:661-666.

40. Bevilaqua, M. P., J. S. Pober, D. L. Mendrick, R. S. Cotran, and M. A. Gimbrone, Jr. 1987. Identification of an inducible endothelialleukocyte adhesion molecule (E-LAM-1) using monoclonal antibodies (Mab). Fed. Proc. 46:405. (Abstr.)

41. Hoover, R. L., R. Folger, W. A. Huering, B. R. Ware, and M. J. Karnovsky. 1980. Adhesion of leukocytes to endothelium: roles of divalent cations, surface charge, chemotactic agents and substrate. $J$. Cell. Sci. 45:73-86.

42. Charo, I. F., C. Yuen, and I. M. Goldstein. 1985. Adherence of human polymorphonuclear leukocytes to endothelial monolayers. Effects of temperature, divalent cations, and chemotactic factors on the 
strength of adherence measured with a new centrifugation assay. Blood. 65:473-479.

43. Kazimierczak, W., M. Plaut, K. A. Knauer, H. L. Meier, and L. M. Lichtenstein. 1984. Deuterium-oxide-induced histamine release from basophils of allergic subjects. Am. Rev. Respir. Dis. 129:592-596.

44. Bochner, B. S., B. K. Rutledge, and R. P. Schleimer. 1987. Interleukin 1 (IL 1) production by human lung tissue II. Inhibition by antiinflammatory steroids. J. Immunol. 139:2303-2307.

45. Capron, A., J. P. Dessaint, M. Capron, M. Joseph, J. C. Ameisen, and A. B. Tonnel. 1986. From parasites to allergy: a second receptor for IgE. Immunol. Today. 7:15-18.

46. Zimmerman, G. A., T. M. McIntyre, and S. M. Prescott. 1985. Thrombin stimulates the adherence of neutrophils to human endothelial cells in vitro. J. Clin. Invest. 76:2235-2246.

47. Wheeler, M. E., F. W. Luscinskas, M. P. Bevilaqua, and M. A. Gimbrone, Jr. 1987. Characterization of an endothelial-derived inhibitor of leukocyte adhesion. Fed. Proc. 46:758. (Abstr.)
48. Berger, M., J. O’Shea, A. S. Cross, T. M. Folks, T. M. Chused, E. J. Brown, and M. M. Frank. 1984. Human neutrophils increase expression of $\mathrm{C} 3 \mathrm{bi}$ as well as $\mathrm{C} 3 \mathrm{~b}$ receptors upon activation. J. Clin. Invest. 74:1566-1571.

49. Todd, R. F., III., M. A. Arnaout, R. E. Rosin, C. A. Crowley, W. A. Peters, and B. M. Babior. 1984. Subcellular localization of the large subunit of Mol (Mol $\alpha$ : formerly gp 110), a surface glycoprotein associated with neutrophil adhesion. J. Clin. Invest. 74:1280-1290.

50. Bainton, D. F., L. J. Miller, T. K. Kishimoto, and T. A. Springer. 1987. Leukocyte adhesion proteins are located in peroxidase-negative granules of human PMN and monocytes: an immunocytochemical study. Fed. Proc. 46:405. (Abstr.)

51. Bussolino, F., F. Breviario, C. Tetta, M. Aglietta, A. Mantovani, and E. Dejana. 1986. Interleukin-1 stimulates platelet-activating factor production in cultured human endothelial cells. J. Clin. Invest. 77:2027-2033. 